\title{
Sodium bicarbonate supplementation prevents skilled tennis performance decline after a simulated match
}

\author{
Ching-Lin Wu', Mu-Chin Shih², Chia-Cheng Yang ${ }^{3}$, Ming-Hsiang Huang ${ }^{3}$, Chen-Kang Chang ${ }^{4 *}$
}

\begin{abstract}
The supplementation of sodium bicarbonate $\left(\mathrm{NaHCO}_{3}\right)$ could increase performance or delay fatigue in intermittent high-intensity exercise. Prolonged tennis matches result in fatigue, which impairs skilled performance. The aim of this study was to investigate the effect of $\mathrm{NaHCO}_{3}$ supplementation on skilled tennis performance after a simulated match. Nine male college tennis players were recruited for this randomized cross-over, placebo-controlled, doubleblind study. The participants consumed $\mathrm{NaHCO}_{3}\left(0.3 \mathrm{~g} \cdot \mathrm{kg}^{-1}\right)$ or $\mathrm{NaCl}\left(0.209 \mathrm{~g} \cdot \mathrm{kg}^{-1}\right)$ before the trial. An additional supplementation of $0.1 \mathrm{~g} . \mathrm{kg}^{-1} \mathrm{NaHCO}_{3}$ or $0.07 \mathrm{~g} . \mathrm{kg}^{-1} \mathrm{NaCl}$ was ingested after the third game in the simulated match. The Loughborough Tennis Skill Test was performed before and after the simulated match. Post-match $\left[\mathrm{HCO}_{3}{ }^{-}\right]$and base excess were significantly higher in the bicarbonate trial than those in the placebo trial. Blood [lactate] was significantly increased in the placebo (pre: $1.22 \pm 0.54$; post: $2.17 \pm 1.46 \mathrm{mM}$ ) and bicarbonate (pre: $1.23 \pm 0.41$; post: $3.21 \pm 1.89 \mathrm{mM}$ ) trials. The match-induced change in blood [lactate] was significantly higher in the bicarbonate trial. Blood $\mathrm{pH}$ remained unchanged in the placebo trial (pre: $7.37 \pm 0.32$; post: $7.37 \pm 0.14$ ) but was significantly increased in the bicarbonate trial (pre: $7.37 \pm 0.26$; post: $7.45 \pm 0.63$ ), indicating a more alkaline environment. The service and forehand ground stroke consistency scores were declined significantly after the simulated match in the placebo trial, while they were maintained in the bicarbonate trial. The match-induced declines in the consistency scores were significantly larger in the placebo trial than those in the bicarbonate trial. This study suggested that $\mathrm{NaHCO}_{3}$ supplementation could prevent the decline in skilled tennis performance after a simulated match.
\end{abstract}

\section{Introduction}

Tennis is an intermittent sport with the actual playing time being $17-28 \%$ of total match duration [1]. The remainder of the time is recovery between points and games. On average, the rallies last 4.3-7.7 sec in men's Grand Slam tournament matches [2]. At the stroke frequency of approximately 0.75 shots. $\sec ^{-1}[2]$, the cumulative effect of the repetitive short-term high-intensity efforts throughout prolonged tennis matches could result in significant neuromuscular fatigue [1,3], which in turn may impair certain aspects of skilled performance $[4,5]$. Indeed, the stroke accuracy was significantly decreased in competitive tennis players near the point of volitional fatigue [6]. Stroke accuracy and

\footnotetext{
* Correspondence: wspahn@seed.net.tw

${ }^{4}$ Sport Science Research Center, National Taiwan College of Physical

Education, 16, Sec 1, Shuan-Shih Rd, Taichung, 404, Taiwan

Full list of author information is available at the end of the article
}

velocity were also significantly decreased after a strenuous training session (average rating of perceived exertion (RPE) 15.9/20) in well-trained tennis players [7].

One of the potential factors that may influence the skilled tennis performance is neural function. The central activation failure, changes in neurotransmitter levels and disturbance in excitation-contraction coupling have been suggested to play an important role in the development of fatigue in prolonged tennis matches $[3,8]$. The decline in maximal voluntary contraction and electromyographic activity of knee extensor muscles occurred progressively during a 3-hour tennis match, indicating a decreasing number of motor units that are voluntarily recruited [3]. The impairments in neural functions in lower limbs may lead to the slower acceleration in movement and the inability to reach the optimal stroke position. In addition, the neural impairments in forearm muscles may result in the poor control of the racquet. 
Alkalinizing agents including sodium bicarbonate $\left(\mathrm{NaHCO}_{3}\right)$ have been proposed as ergogenic aids for their potential effects on providing enhanced extracellular buffer capacity, leading to the elevated proton $\left(\mathrm{H}^{+}\right)$efflux from the contracting musculature $[9,10]$. The increased intramuscular $\left[\mathrm{H}^{+}\right]$during exercise has been considered as one of the major causes of muscle fatigue [11]. It has been suggested that $\mathrm{H}^{+}$accumulation would inhibit the enzymes involved in oxidative phosphorylation and glycolysis. It would also reduce $\mathrm{Ca}^{2+}$ binding to troponin $\mathrm{C}$ and inhibit the sarcoplasmic reticulum enzyme $\mathrm{Ca}^{2+}$-ATPase $[11,12]$. Indeed, previous studies generally agreed that $\mathrm{NaHCO}_{3}$ supplementation was beneficial for the performance in a single bout of high-intensity exercise lasting 17 min [13,14], and intermittent short-term high-intensity exercise [15-17]. It has also been shown that $\mathrm{NaHCO}_{3}$ supplementation increased the total work output during a 1-hr competitive cycling [18]. Furthermore, $\mathrm{NaHCO}_{3}$ supplementation could improve total power output in a 30 min high-intensity intermittent cycling exercise representative of various ball games [19]. Nevertheless, several studies failed to find ergogenic effect of $\mathrm{NaHCO}_{3}$ supplementation on exhaustive short-term cycling [20] or resistance exercise [21].

Recently, the potential role of $\mathrm{NaHCO}_{3}$ supplementation in alleviating the exercise-induced impairment in the neural functions has been proposed. $\mathrm{NaHCO}_{3}$ supplementation has been shown to increase muscle fiber conduction velocity and reduce force decline in sustained maximal contraction after a 50-min submaximal cycling [22]. With the potential role of $\mathrm{NaHCO}_{3}$ in preserving the neural functions after prolonged exercise, we hypothesized that $\mathrm{NaHCO}_{3}$ supplementation may prevent the fatigue-induced decline in skilled tennis performance. The aim of this study was to investigate the effect of $\mathrm{NaHCO}_{3}$ supplementation on skilled tennis performance after a simulated match.

\section{Materials and methods}

\section{Participants}

Nine male Division I college tennis players (age $21.8 \pm$ 2.4 years; height $1.73 \pm 0.07 \mathrm{~m}$ ) were recruited. All participants have competed in the national level. All participants were given their written informed consent. The study protocol was approved by the Human Subject Committee of National Taiwan College of Physical Education.

\section{Experimental design}

This study used a randomized cross-over, placebo-controlled, double-blind design. Each participant completed 2 experimental trials, bicarbonate and placebo, in a randomized order. The 2 trials were separated by 1 week. The schedule of dietary supplementation, exercise test, and blood sampling is shown in Figure 1. All trials were performed in the same outdoor tennis court with a hard surface. The temperature at the start of the exercise was $34.5 \pm 3.2^{\circ} \mathrm{C}$ and $34.4 \pm 3.4^{\circ} \mathrm{C}$ in the placebo and bicarbonate trial, respectively. The relative humidity was 47.5 $\pm 3.0 \%$ and $47.2 \pm 3.6 \%$ in the placebo and bicarbonate trial, respectively. They were not significantly different between the trials. The participants familiarized with the test protocol and court in a training session 1 week before the experiment. The participants were instructed to maintain their training schedule and to consume exactly the same diet for 2 days before each trial. All participants were also asked to abstain from alcohol, caffeine, and tobacco consumption for 48 hours before each trial.

On the experimental days, the participants reported to the laboratory after an overnight fast. Body composition and body weight were measured using bioimpedance analysis method (InBody 3.0, Biospace, Seoul, Korea) before obtaining fasting blood samples. In the two trials, the participants had similar body weight (placebo: 67.90 $\pm 11.38 \mathrm{~kg}$; bicarbonate: $68.04 \pm 11.31 \mathrm{~kg}$ ) and body fat (placebo: $16.11 \pm 5.01 \%$; bicarbonate: $15.48 \pm 4.79 \%$ ).

\section{Dietary protocol}

After given fasting blood samples, the participants consumed $\mathrm{NaHCO}_{3}\left(0.3 \mathrm{~g} \mathrm{~kg}^{-1}\right.$ body mass) or placebo $\left(\mathrm{NaCl}, 0.209 \mathrm{~g} \mathrm{~kg}^{-1}\right.$, equal amount of sodium) in $250 \mathrm{ml}$ water. A standard breakfast (1.5 g. $\mathrm{kg}^{-1}$ carbohydrate, including white bread, jam, and glucose drink) was



Figure 1 Experimental design of the study. LTST: Loughborough tennis skill test; $\uparrow: \mathrm{NaHCO}_{3}$ or placebo supplementation; (black triangle): blood sampling. 
ingested $20 \mathrm{~min}$ after the drink consumption. A $100 \mathrm{ml}$ drink containing $0.1 \mathrm{~g}$. $\mathrm{kg}^{-1} \mathrm{NaHCO}_{3}$ or $0.07 \mathrm{~g}$. $\mathrm{kg}^{-1}$ $\mathrm{NaCl}$ was ingested after the third game in the simulated match.

\section{Tennis skill test}

The Loughborough Tennis Skill Test [4] was performed before and after the simulated match. Briefly, the test measured the accuracy and consistency of service and forehand and backhand ground stroke to both sides of the court. The players served 10 balls each at match pace from the right and left service area. The target was a $4.0 \mathrm{~m} \times 0.6 \mathrm{~m}$ region marked at the end portion of the service box in the opposite court. Subsequently, the players performed forehand and backhand ground strokes cross-court and down the line with 10 balls each. The balls were fed by a ball serving machine (Tennis Tower Competitor, Sports Tutor Inc., Burbank, CA, USA) at the pace of 15 balls per min. A $1.5 \mathrm{~m} \times 1.5 \mathrm{~m}$ target was placed in the rear corner of both singles court areas. The accuracy score was the number of balls which were landed on the designated target. The consistency score was the number of balls landed within the singles court on the designated side (excluding the target). The entire tests were recorded by a digital video camera for latter examination to ensure the accuracy of records. The on-site scoring and video analysis were performed by the same research personnel who were blind to the treatment.

\section{The simulated match}

The simulated match consisted of 12 games, alternating receiving and service games. Each game consisted of 6 points and 6 balls were hit in each point. The balls were fed at the frequency of 6 balls $/ 10 \mathrm{sec}$ by a ball serving machine. The receiving games (game 1, 3, 5, 7, 9 and 11) started from a forehand ground stroke, followed by 2 backhand ground strokes, a forehand ground stroke, and 2 volleys. The service games (game 2, 4, 6, 8, 10 and 12) started from a service, followed by 2 backhand ground strokes, a forehand ground stroke, and 2 volleys. The participants were asked to return to the central line during the ground strokes, and to approach to the net during volleys. A $20 \mathrm{sec}$ break was allowed between each point, and a $90 \mathrm{sec}$ break was allowed after game $3,5,7,9$ and 11 . The entire simulated match lasted approximately $50 \mathrm{~min}$.

Heart rate was monitored throughout the study period using a short-ranged telemeter (EXEL SPORT, Cardiosport, West Sussex, UK). The RPE was recorded using the Borg scale before and after the skill tests and each game of the simulated match. Water was given ad libitum in the first trial, and the timing and amount of consumption were recorded. The same timing and amount of water consumption were repeated in the second trial. The average water consumption during the trials was $1089 \pm 283 \mathrm{ml}$.

\section{Blood sampling and analysis}

Blood samples were taken from a forearm vein by a trained nurse. The post-exercise blood samples were taken immediately after the simulated game. The needles were rinsed with $0.2 \%$ heparin before the sampling. A plastic seal was immediately applied to the syringe after blood collection to avoid the contact with the ambient air. The blood samples were put in ice bath and sent to the laboratory for analysis immediately.

Blood [lactate] was measured with a commercial kit (Roche Diagnostics, Indianapolis, IN, USA) using an autoanalyzer (Beckman SYNCHRON LX20 PRO, Fullerton, $\mathrm{CA}, \mathrm{USA})$. Blood $\left[\mathrm{HCO}_{3}{ }^{-}\right], \mathrm{pH}$, hemoglobin, and base excess were analyzed using a blood gas analyzer (Synthesis 25, Instrumentation Laboratory, Lexington, MA, USA). Blood [lactate] and $\left[\mathrm{HCO}_{3}{ }^{-}\right]$were adjusted to the change in plasma volume [23].

\section{Statistical analysis}

All values were expressed as means \pm standard deviation. A two-way analysis of variance (ANOVA) with repeated measures was used to analyze the biochemical parameters and skill test scores. The independent variables included trial (bicarbonate and placebo) and time (before and after the simulated match). The trial $\times$ time interaction effect was used to test the null hypothesis of no difference in change over time between the 2 trials. When a significant main effect was found, the RyanHolm-Bonferroni step-wise method was used to determine the location of the variance [24]. The effect size of a variable was calculated with the following equation:

$$
\begin{aligned}
\text { Effect size }= & \mid \text { mean before the trial }- \text { mean after the trial } \mid / \\
& \text { standard deviation before the trial }
\end{aligned}
$$

The analysis was performed with SPSS 10.0. A P-value less than 0.05 was considered statistically significant.

\section{Results}

Blood $\left[\mathrm{HCO}_{3}{ }^{-}\right]$remained unchanged after the match in the placebo trial (pre: $27.99 \pm 2.02$; post: $26.37 \pm 3.50$ $\mathrm{mM}$ ) but was significantly elevated in the bicarbonate trial (pre: $29.84 \pm 2.16$; post: $37.98 \pm 3.15 \mathrm{mM}, \mathrm{p}<0.05$; effect size $=4.23$ ) (Figure 2). The match-induced change in blood $\left[\mathrm{HCO}_{3}{ }^{-}\right]$was significantly different between the 2 trials (interaction effect $\mathrm{p}<0.001$; effect size $=2.92$ ). Base excess showed opposite patterns between the 2 trials. The post-match base excess was significantly lower than the pre-match level in the placebo trial (pre: $2.46 \pm 1.68$; post: $0.12 \pm 2.15 \mathrm{mM}, \mathrm{p}<0.05$; effect size $=$ 


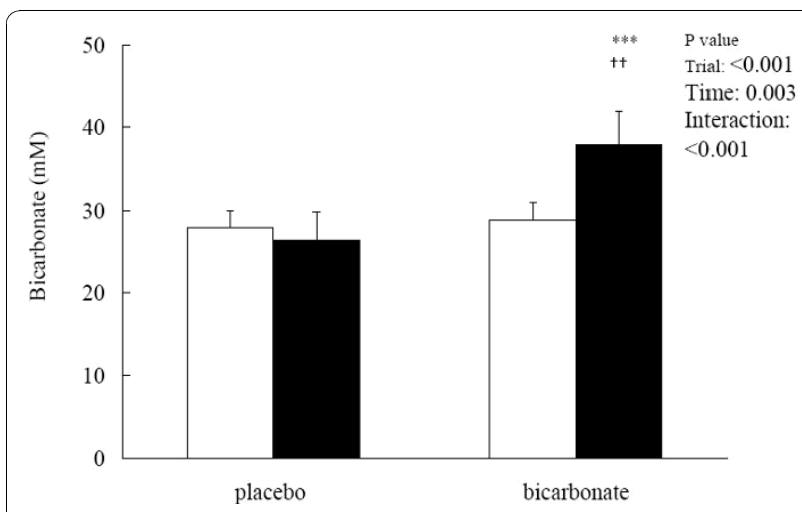

Figure 2 Blood bicarbonate concentrations before (white square) and after (black square) the simulated match in placebo and bicarbonate trials. ${ }^{* *} p<0.001$, before vs after in the same trial; ${ }^{+\dagger} p<0.01$, bicarbonate vs placebo trial.

1.39) but was significantly elevated in the bicarbonate trial (pre: $3.08 \pm 1.47$; post: $11.36 \pm 3.70 \mathrm{mM}, \mathrm{p}<0.05$; effect size $=5.63$ ) (Figure 3$)$. Post-match $\left[\mathrm{HCO}_{3}^{-}\right]$and base excess were significantly higher in the bicarbonate trial than those in the placebo trial. Blood [lactate] was significantly increased after the match in both placebo (pre: $1.22 \pm 0.54$; post: $2.17 \pm 1.46 \mathrm{mM}, \mathrm{p}<0.05$; effect size $=1.76$ ) and bicarbonate (pre: $1.23 \pm 0.41$; post: 3.21 $\pm 1.89 \mathrm{mM}, \mathrm{p}<0.05$; effect size $=4.83$ ) trials (Figure 4). The match-induced change in blood [lactate] was significantly higher in the bicarbonate trial than that in the placebo trial (interaction effect $\mathrm{p}<0.05$; effect size $=$ 1.73). Blood $\mathrm{pH}$ remained unchanged after the match in the placebo trial (pre: $7.37 \pm 0.32$; post: $7.37 \pm 0.14, \mathrm{p}>$ $0.05)$ but was significantly increased in the bicarbonate trial (pre: $7.37 \pm 0.26$; post: $7.45 \pm 0.63$, $\mathrm{p}<0.05$; effect size $=0.31)$ (Figure 5).

The accuracy and consistency scores of service and ground stroke in the Loughborough Tennis Skill Tests

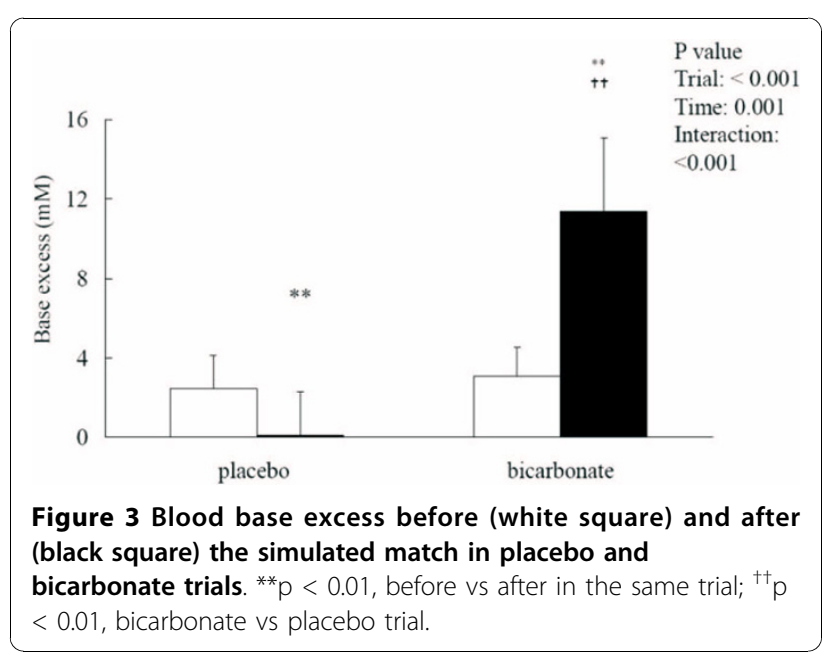

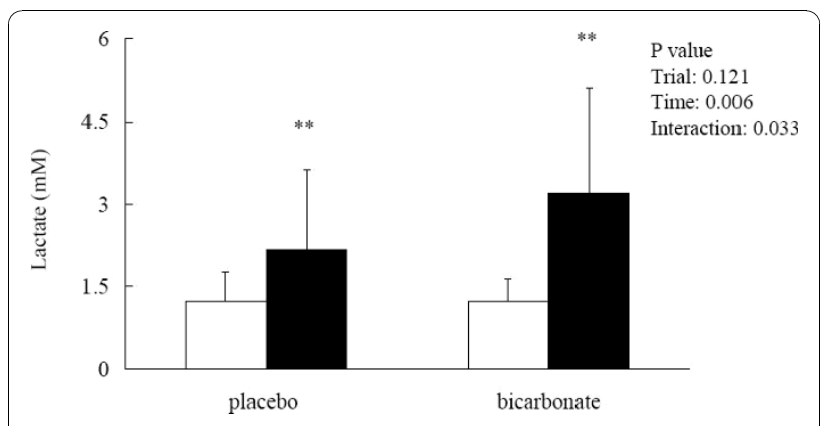

Figure 4 Blood lactate concentrations before (white square) and after (black square) the simulated match in placebo and bicarbonate trials. ${ }^{* *} p<0.01$, before vs after in the same trial.

before and after the simulated match in both trials are presented in Table 1. The service consistency was significantly decreased after the simulated match in the placebo trial (95\% confidence interval (CI) before: 12.721.1; after: 6.5-15.7; $\mathrm{p}<0.05)$, but remained unchanged in the bicarbonate trial. The effect size for service consistency was 1.07 and 0.04 in the placebo and bicarbonate trial, respectively. The match-induced decline in service consistency was significantly larger in the placebo trial compared to that in the bicarbonate trial (interaction effect $\mathrm{p}=0.004$; effect size $=1.26$ ). The $95 \%$ CI for the forehand ground stroke consistency before and after the placebo trial was 8.3-12.7 and 7.6-10.6, respectively. The $95 \% \mathrm{CI}$ for the forehand ground stroke consistency before and after the bicarbonate trial was 6.8-9.2 and 7.3-11.3, respectively. The match-induced decline in forehand ground stroke consistency was also significantly larger in the placebo trial than that in the bicarbonate trial (interaction effect $\mathrm{p}=0.046$; effect size $=2.06)$.

The average heart rate after each game in the simulated match was $173 \pm 13$ and $170 \pm 20$ beats. min $^{-1}$ in the placebo and bicarbonate trial, respectively $(\mathrm{p}>0.05)$.

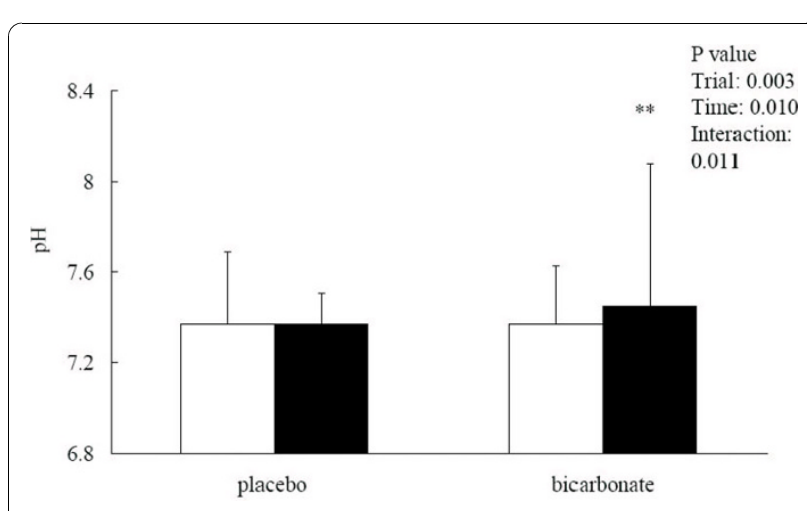

Figure 5 Blood pH before (white square) and after (black square) the simulated match in placebo and bicarbonate trials. ${ }^{* *} p<0.01$, before vs after in the same trial. 
Table 1 The consistency and accuracy scores of service and ground stroke before and after the simulated game in placebo and bicarbonate trials (mean \pm standard deviation)

\begin{tabular}{|c|c|c|c|c|c|c|c|}
\hline & \multicolumn{2}{|c|}{ Placebo } & \multicolumn{2}{|c|}{ Bicarbonate } & \multicolumn{3}{|c|}{ Main effect (P-value) } \\
\hline & Before & After & Before & After & Trial & Time & Interaction \\
\hline \multicolumn{8}{|l|}{ Service (out of 20) } \\
\hline Accuracy & $4.1 \pm 1.8$ & $4.5 \pm 1.5$ & $3.2 \pm 2.6$ & $3.8 \pm 1.9$ & 0.215 & 0.254 & 0.844 \\
\hline Consistency & $16.9 \pm 5.4$ & $11.1 \pm 6.0^{\dagger}$ & $13.8 \pm 5.1$ & $13.6 \pm 5.9$ & 0.861 & 0.059 & $0.004^{* *}$ \\
\hline \multicolumn{8}{|c|}{$\overline{\text { Gs-Total }^{a} \text { (out of } 40 \text { ) }}$} \\
\hline Accuracy & $5.5 \pm 3.3$ & $5.2 \pm 2.5$ & $6.0 \pm 3.1$ & $5.3 \pm 2.2$ & 0.758 & 0.446 & 0.694 \\
\hline Consistency & $19.5 \pm 4.2$ & $17.1 \pm 4.3$ & $17.6 \pm 2.8$ & $19.0 \pm 4.5$ & 1.000 & 0.575 & 0.088 \\
\hline \multicolumn{8}{|c|}{ Gs-Forehand (out of 20) } \\
\hline Accuracy & $3.5 \pm 1.5$ & $2.7 \pm 2.1$ & $3.7 \pm 1.9$ & $2.3 \pm 1.2$ & 0.850 & 0.065 & 0.493 \\
\hline Consistency & $10.5 \pm 2.8$ & $9.1 \pm 2.0$ & $8.0 \pm 1.6$ & $9.3 \pm 2.6$ & 0.237 & 0.943 & $0.046^{*}$ \\
\hline \multicolumn{8}{|c|}{ Gs-Backhand (out of 20) } \\
\hline Accuracy & $2.0 \pm 2.1$ & $2.3 \pm 1.0$ & $2.2 \pm 1.8$ & $1.8 \pm 1.9$ & 0.868 & 1.000 & 0.464 \\
\hline Consistency & $9.4 \pm 2.7$ & $8.0 \pm 2.5$ & $9.7 \pm 2.7$ & $9.5 \pm 3.0$ & 0.391 & $0.046^{*}$ & 0.475 \\
\hline
\end{tabular}

${ }^{\mathrm{a} G S}$ : ground stroke; ${ }^{*} \mathrm{p}<0.05,{ }^{* *} \mathrm{p}<0.01 ;{ }^{\dagger} \mathrm{p}<0.05$, before vs after in the same trial.

The RPE after the simulated game was $15.7 \pm 1.9$ in the placebo trial and $15.2 \pm 2.8$ in the bicarbonate trial $(\mathrm{p}>$ $0.05)$.

The levels of hematocrit before and after the placebo trial were $44.8 \pm 3.1$ and $43.7 \pm 2.6 \%$, respectively. The levels before and after the bicarbonate trial were $45.7 \pm$ 2.4 and $44.2 \pm 2.2 \%$, respectively. The match-induced changes in hematocrit were insignificant in both trials, indicating the adequate hydration status of the participants during the trials.

\section{Discussion}

The results of this study suggested that $\mathrm{NaHCO}_{3}$ supplementation could prevent the decline in skilled tennis performance after a simulated match. The service and forehand ground stroke consistency was maintained after a simulated match in the bicarbonate trial. On the other hand, these consistency scores were decreased after the match in the placebo trial. Furthermore, in forehand and backhand ground strokes combined, the consistency showed a trend of decrease after the simulated match in the placebo trial (effect size $=0.57$ ) while it increased slightly in the bicarbonate trial (effect size = 0.50 ) (interaction effect $\mathrm{p}=0.088$ ). To our knowledge, this is the first study that showed the effect of $\mathrm{NaHCO}_{3}$ supplementation on skilled performance in racquet sports.

Previous studies have focused on the effect of $\mathrm{NaHCO}_{3}$ on physical performance $[14,18,25,26]$. Only two studies investigated the effect of $\mathrm{NaHCO}_{3}$ supplementation on skilled sport performance [16,27]. It was reported that $\mathrm{NaHCO}_{3}$ supplementation could increase punch efficacy, the number of successful punches thrown and landed, by $5 \%$ in real boxing matches [27].
Another study revealed that $\mathrm{NaHCO}_{3}$ supplementation increased the number of judo-specific throws (ippon seo $i$ nague) completed in the second and third round of a 3round test. These authors contributed the effect of $\mathrm{NaHCO}_{3}$ supplementation to the enhanced extracelluar buffer capacity, lower intramuscular acidity, and increased strong ion difference which may affect $\mathrm{Ca}^{2+}$ release in skeletal muscle [16,27]. Interestingly, these 2 studies also reported no effect of $\mathrm{NaHCO}_{3}$ supplementation on RPE, similar to our results. It suggested that $\mathrm{NaHCO}_{3}$ supplementation may increase skilled performance without the impact on psychological perception of fatigue.

In this study, blood [lactate] after the simulated match was $2.17 \pm 1.46$ and $3.21 \pm 1.89 \mathrm{mM}$ in the placebo and bicarbonate trial, respectively. The concentrations were similar to the previously reported results of $1.5-2.3 \mathrm{mM}$ after real tennis match plays [28,29]. The induced alkalosis and increased post-match [lactate] in the bicarbonate trial were similar to the results in previous studies $[15,19,30]$. The significantly higher post-match $\left[\mathrm{HCO}_{3}{ }^{-}\right]$ and base excess in the bicarbonate trial indicated enhanced extracellular buffer capacity. As the result, blood $\mathrm{pH}$ was significantly increased despite a significant increase in [lactate] after the simulated game in the bicarbonate trial. The increased extracellular buffer capacity and extracellular $\mathrm{pH}$ could result in higher $\left[\mathrm{H}^{+}\right]$ gradient across the sarcolemma. This may lead to higher $\mathrm{H}^{+}$and lactate efflux from working muscles via monocarboxylate co-transporter, a symport carrier of lactate and $\mathrm{H}^{+}$[30-33].

One of the potential factors that may influence the skilled tennis performance is neural function. It has been shown that central activation failure, changes in 
neurotransmitter concentrations, inhibition of motoneuron excitability, and disturbance in excitation-contraction coupling may contribute to the development of fatigue in prolonged tennis matches [8]. The central activation deficit of knee extensor muscles occurred progressively during a 3-hour tennis match, indicating a decreasing number of motor units that are voluntarily recruited [3]. Similarly, a decrease in neural drive to the motor unit has also been shown in other types of highintensity intermittent exercise $[34,35]$. In tennis, sprints usually occur over very short distances where athletes are unable to reach the maximum speed. Thus, the initial acceleration phase is more important than the maximum speed in the on-court movements [36]. The impairments in neural functions may lead to the slower acceleration in movement and the inability to reach the optimal stroke position. The neural impairments in forearm muscles may also result in the poor control of the racquet. These factors may be partially responsible for the decrease in the skilled performance after the simulated game in our placebo trial, as well as the decreases in ball speed and precision in serve and forehand and backhand strokes after a 2-hr training session [7]. Some evidence suggested that $\mathrm{NaHCO}_{3}$ supplementation may alleviate the exercise-induced impairment in the neural functions. $\mathrm{NaHCO}_{3}$ supplementation has been shown to increase muscle fiber conduction velocity and reduce force decline in sustained maximal contraction after a 50-min submaximal cycling [22]. An in vitro study also revealed that alkalosis induced by high [ $\left.\mathrm{HCO}^{-}\right]$resulted in an increase in twitch tension in isolated rat phrenic nerve-hemidiaphragm after electrical stimulations [37]. Therefore, it is possible that $\mathrm{NaHCO}_{3}$ could help to restore certain level of neural functions after the simulated match, resulting in the better skilled performance in the bicarbonate trial. The effect of $\mathrm{NaHCO}_{3}$ supplementation on neural functions requires further research.

It has been argued that intracellular $\mathrm{H}^{+}$and lactate may not be the major factors in muscular fatigue [38-41]. Similarly, this study showed that $\mathrm{NaHCO}_{3}$ supplementation could prevent fatigue-induced decline in performance on the condition of moderate blood [lactate] and unchanged blood $\mathrm{pH}$. The predominant energy source of the short, high-intensity strokes in the Loughborough Tennis Skill Test is phosphocreatine (PCr) because blood [lactate] was only $0.9 \pm 0.1 \mathrm{mM}$ after the test [4]. Some studies have proposed that the supplementation of $\mathrm{NaHCO}_{3}$ could reduce $\mathrm{PCr}$ degradation and increase the power output required to induce the onset of rapid increase in [inorganic phosphate $(\mathrm{Pi})] /[\mathrm{PCr}]$ in forearm muscles during incremental wrist-flexion exercise to volitional fatigue $[42,43]$. However, creatine supplementation had no effect on power and accuracy of tennis strokes in studies of which test protocols were similar to the present study $[44,45]$. These results suggested that muscle acidosis and creatine content may not be the major factors in the decline in skilled tennis performance as exemplified in this study.

The Loughborough Tennis Skill Test is an optimal method for measuring the fatigue-induced decline in tennis skills as the accuracy of service and groundstroke was significantly declined after volitional fatigue [4]. In addition, the groundstroke accuracy was significantly decreased after the middle of the test [6]. Our results also showed that the consistency of service and forehand ground stroke was impaired after a simulated match in the placebo trial, while it was maintained in the bicarbonate trial.

The current study presented the similar skill level of players to those in the previous studies [4,6]. In Davey et al. [4] the average accuracy and consistency scores of service (out of 20) were 4.0 and 9.0, respectively. The average accuracy and consistency scores (out of 20) were 1.5 and 11.3 for forehand ground stroke and 1.8 and 10.4 for backhand ground stroke, respectively. Another study showed a total ground stroke accuracy of $11.8 \%$ at the baseline [6]. These indicated that the Loughborough Tennis Skill Test was a suitable measurement for the skills in the present study.

To hit the areas designated for 'accuracy' was a difficult task. The average service accuracy before the simulated match in both trials combined was $18.5 \%$ (3.7 out of 20), while the average ground stroke accuracy was $14.5 \%$ ( 5.8 out of 40 ). It is possible that should the metabolic and/or neural functions be improved, our participants still could not show the improvements in these difficult tasks. Therefore, the improvement may be more apparent in the relatively easier skills such as the consistency.

The absolute intensity of the simulated match used in this study was lower than that in Grand Slam tournaments [2]. This is understandable because our participants were at the national level. Our participants performed 1.67 shots. sec $^{-1}$, compared to approximately 0.75 shots. sec $^{-1}$ in men's singles in Grand Slams. Each point in our simulated match lasted 10 sec, compared to 4-8 sec in Grand Slams. However, the relative intensity was high. The average heart rate of our participants during the simulated match was approximately $85 \%$ of their age-predicted maximal heart rate, similar to $86.2 \%$ reported in American Division I collegiate men's singles [29]. It is difficult to design a simulated match that is representative of most real matches as athletes are different in their playing styles, such as baseline or serve and volley. Therefore, the simulated match was designed to include the 3 major types of play, volley, forehand strokes and backhand strokes. 
There were several limitations of this study. The content of simulated match was not completely consistent with real tennis matches. The duration of the simulated match was a little shorter than most of the real ones. The psychological strain in real matches was also absent in the simulated match. Secondly, the participants were in free living style between the 2 trials. Although they were asked to maintain their physical activity and dietary patterns before each trial, we could not rule out the possibility that they may not fully comply with the instructions. Thirdly, the participants' motivation to perform with their best effort, including hitting the ball with the maximal power, may also affect the results.

\section{Conclusions}

In conclusion, $\mathrm{NaHCO}_{3}$ supplementation could prevent the decline in skilled tennis performance after a simulated match. Future research may include other tennis skills such as volley and drop shot with the measurement of stroke velocity and running speed. The effect of alkalosis on neuromuscular functions and psychological variables such as reactive, anticipatory, and decisionmaking capacities also warrant further investigation.

\section{Author details \\ ${ }^{1}$ Graduate Institute of Sports and Health Management, National Chung Hsing University, 250 Kuo Kuang Road, Taichung, 402, Taiwan. ${ }^{2}$ Department of Laboratory Medicine, China Medical University and Hospital, 91 Hsueh- Shih Rd, Taichung, 404, Taiwan. ${ }^{3}$ Department of Athletics, National Taiwan College of Physical Education, 16, Sec 1, Shuan-Shih Rd, Taichung, 404, Taiwan. ${ }^{4}$ Sport Science Research Center, National Taiwan College of Physical Education, 16, Sec 1, Shuan-Shih Rd, Taichung, 404, Taiwan.}

\section{Authors' contributions}

CLW designed the study and assisted the manuscript preparation. MCS carried out blood analysis and assisted the manuscript preparation. CCY assisted the study design and was responsible for conducting the study, including subject recruitment, skill test and data analysis. MHH assisted the design of the study and manuscript preparation. CKC was responsible for statistical analysis and manuscript preparation. All authors have read and approved the final manuscript.

\section{Competing interests}

The authors declare that they have no competing interests.

Received: 7 May 2010 Accepted: 26 October 2010

Published: 26 October 2010

\section{References}

1. Hornery DJ, Farrow D, Mujika I, Young W: Fatigue in tennis: mechanisms of fatigue and effect on performance. Sports Med 2007, 37:199-212.

2. O'Donoghue $P$, Ingram B: A notational analysis of elite tennis strategy. $J$ Sports Sci 2001, 19:107-15.

3. Girard O, Lattier G, Maffiuletti NA, Micallef JP, Millet GP: Neuromuscular fatigue during a prolonged intermittent exercise: Application to tennis. $J$ Electromyogr Kinesiol 2008, 18:1038-46.

4. Davey PR, Thorpe RD, Williams C: Fatigue decreases skilled tennis performance. J Sports Sci 2002, 20:311-8.

5. Mendez-Villanueva A, Fernandez-Fernandez J, Bishop D: Exercise-induced homeostatic perturbations provoked by singles tennis match play with reference to development of fatigue. Br J Sports Med 2007, 41:717-22.
6. Davey PR, Thorpe RD, Willams C: Simulated tennis matchplay in a controlled environment. J Sports Sci 2003, 21:459-67.

7. Vergauwen L, Spaepen AJ, Lefevre J, Hespel P: Evaluation of stroke performance in tennis. Med Sci Sports Exerc 1998, 30:1281-8.

8. Girard O, Millet GP: Neuromuscular fatigue in racquet sports. Neurol Clin 2008, 26:181-94.

9. Matson LG, Tran ZV: Effects of sodium bicarbonate ingestion on anaerobic performance: a meta-analytic review. Int J Sport Nutr 1993, 3:2-28.

10. Requena B, Zabala M, Padial P, Feriche B: Sodium bicarbonate and sodium citrate: ergogenic aids? J Strength Cond Res 2005, 19:213-24.

11. Fitts RH: Cellular mechanisms of muscle fatigue. Physiol Rev 1994, 74:49-94.

12. Allen DG, Westerblad $H$, Lannergren J: The role of intracellular acidosis in muscle fatigue. Adv Exp Med Biol 1995, 384:57-68.

13. Lindh AM, Peyrebrune MC, Ingham SA, Bailey DM, Folland JP: Sodium bicarbonate improves swimming performance. Int J Sports Med 2008, 29:519-23.

14. McNaughton LR, Siegler J, Midgley A: Ergogenic effects of sodium bicarbonate. Curr Sports Med Rep 2008, 7:230-6.

15. Bishop D, Edge J, Davis C, Goodman C: Induced metabolic alkalosis affects muscle metabolism and repeated-sprint ability. Med Sci Sports Exerc 2004, 36:807-13.

16. Artioli GG, Gualano B, Coelho DF, Benatti FB, Gailey AW, Lancha AH Jr: Does sodium-bicarbonate ingestion improve simulated judo performance? Int J Sport Nutr Exerc Metab 2007, 17:206-17.

17. Siegler JC, Keatley S, Midgley AW, Nevill AM, McNaughton LR: Pre-exercise alkalosis and acid-base recovery. Int J Sports Med 2008, 29:545-51.

18. McNaughton L, Dalton B, Palmer G: Sodium bicarbonate can be used as an ergogenic aid in high-intensity, competitive cycle ergometry of $1 \mathrm{~h}$ duration. Eur J Appl Physiol Occup Physiol 1999, 80:64-9.

19. Price $M$, Moss $P$, Rance $S$ : Effects of sodium bicarbonate ingestion on prolonged intermittent exercise. Med Sci Sports Exerc 2003, 35:1303-8.

20. Vanhatalo A, McNaughton LR, Siegler J, Jones AM: Effect of Induced Alkalosis on the Power-Duration Relationship of 'All-Out' Exercise. Med Sci Sports Exerc 2010, 42(3):563-70.

21. Portington KJ, Pascoe DD, Webster MJ, Anderson LH, Rutland RR, Gladden LB: Effect of induced alkalosis on exhaustive leg press performance. Med Sci Sports Exerc 1998, 30:523-8.

22. Hunter AM, De Vito G, Bolger C, Mullany H, Galloway SD: The effect of induced alkalosis and submaximal cycling on neuromuscular response during sustained isometric contraction. J Sports Sci 2009, 27:1261-9.

23. Costill DL, Fink WJ: Plasma volume changes following exercise and thermal dehydration. J Appl Physiol 1974, 37:521-5.

24. Atkinson $\mathrm{G}$ : Analysis of repeated measurements in physical therapy research: multiple comparisons amongst level means and multi-factorial designs. Phys Ther Sport 2002, 3:191-203.

25. Douroudos II, Fatouros IG, Gourgoulis V, Jamurtas AZ, Tsitsios T, Hatzinikolaou A, Margonis K, Mavromatidis K, Taxildaris K: Dose-related effects of prolonged $\mathrm{NaHCO} 3$ ingestion during high-intensity exercise. Med Sci Sports Exerc 2006, 38:1746-53.

26. Edge J, Bishop D, Goodman C: Effects of chronic NaHCO3 ingestion during interval training on changes to muscle buffer capacity, metabolism, and short-term endurance performance. J Appl Physiol 2006, 101:918-25.

27. Siegler JC, Hirscher K: Sodium bicarbonate ingestion and boxing performance. J Strength Cond Res 2010, 24:103-8.

28. Ferrauti A, Bergeron MF, Pluim BM, Weber K: Physiological responses in tennis and running with similar oxygen uptake. Eur J Appl Physiol 2001, 85:27-33.

29. Bergeron M, Maresh C, Kraemer W, Abraham A, Conroy B, Gabaree C Tennis: a physiological profile during match play. Int J Sports Med 1991, 12:474-9.

30. Stephens TJ, McKenna MJ, Canny BJ, Snow RJ, McConell GK: Effect of sodium bicarbonate on muscle metabolism during intense endurance cycling. Med Sci Sports Exerc 2002, 34:614-21.

31. Nielsen HB, Bredmose PP, Stromstad M, Volianitis S, Quistorff B, Secher NH: Bicarbonate attenuates arterial desaturation during maximal exercise in humans. J Appl Physiol 2002, 93:724-31. 
32. Hollidge-Horvat MG, Parolin ML, Wong D, Jones NL, Heigenhauser GJ: Effect of induced metabolic alkalosis on human skeletal muscle metabolism during exercise. Am J Physiol Endocrinol Metab 2000, 278: E316-29.

33. Galloway SD, Maughan RJ: The effects of induced alkalosis on the metabolic response to prolonged exercise in humans. Eur J Appl Physiol Occup Physiol 1996, 74:384-9.

34. Taylor JL, Allen GM, Butler JE, Gandevia SC: Supraspinal fatigue during intermittent maximal voluntary contractions of the human elbow flexors. J Appl Physiol 2000, 89:305-13.

35. Racinais S, Bishop D, Denis R, Lattier G, Mendez-Villaneuva A, Perrey S. Muscle deoxygenation and neural drive to the muscle during repeated sprint cycling. Med Sci Sports Exerc 2007, 39:268-74.

36. Parsons LS, Jones MT: Development of speed, agility and quickness for tennis athletes. Strength Cond 1998, 20:14-9.

37. Ono K, Nagano O, Ohta Y, Kosaka F: Neuromuscular effects of respiratory and metabolic acid-base changes in vitro with and without nondepolarizing muscle relaxants. Anesthesiology 1990, 73:710-6.

38. Nielsen OB, de Paoli F, Overgaard K: Protective effects of lactic acid on force production in rat skeletal muscle. J Physiol 2001, 536:161-6.

39. Pedersen TH, Nielsen OB, Lamb GD, Stephenson DG: Intracellular acidosis enhances the excitability of working muscle. Science 2004, 305:1144-7.

40. Posterino GS, Dutka TL, Lamb GD: L(+)-lactate does not affect twitch and tetanic responses in mechanically skinned mammalian muscle fibres. Pflugers Arch 2001, 442:197-203.

41. Robergs RA, Ghiasvand F, Parker D: Biochemistry of exercise-induced metabolic acidosis. Am J Physiol Regul Integr Comp Physiol 2004, 287: R502-16.

42. Forbes SC, Raymer GH, Kowalchuk JM, Marsh GD: NaHCO3-induced alkalosis reduces the phosphocreatine slow component during heavyintensity forearm exercise. J Appl Physiol 2005, 99:1668-75.

43. Raymer GH, Marsh GD, Kowalchuk JM, Thompson RT: Metabolic effects of induced alkalosis during progressive forearm exercise to fatigue. J Appl Physiol 2004, 96:2050-6.

44. Pluim BM, Ferrauti A, Broekhof F, Deutekom M, Gotzmann A, Kuipers H, Weber $K$ : The effects of creatine supplementation on selected factors of tennis specific training. Br J Sports Med 2006, 40:507-11.

45. Op 't Eijnde B, Vergauwen L, Hespel P: Creatine loading does not impact on stroke performance in tennis. Int I Sports Med 2001, 22:76-80.

doi:10.1186/1550-2783-7-33

Cite this article as: Wu et al: Sodium bicarbonate supplementation prevents skilled tennis performance decline after a simulated match. Journal of the International Society of Sports Nutrition 2010 7:33.

\section{Submit your next manuscript to BioMed Central and take full advantage of:}

- Convenient online submission

- Thorough peer review

- No space constraints or color figure charges

- Immediate publication on acceptance

- Inclusion in PubMed, CAS, Scopus and Google Scholar

- Research which is freely available for redistribution

Submit your manuscript at www.biomedcentral.com/submit 